\title{
MECHANICAL AND OPTICAL INVESTIGATION OF LASER WELDED STRUCTURAL STEEL - POLY(METHYL-METHACRYLATE) HYBRID JOINT STRUCTURES
}

\author{
TAmÁs CsiszéR ${ }^{a, b, *}$, TAmás Temesi ${ }^{c}$, LÁszló MolnáR ${ }^{a}$ \\ ${ }^{a}$ Edutus University, Engineering Institute, Stúdium tér 1., 2800 Tatabánya, Hungary \\ ${ }^{b}$ Óbuda University, Sándor Rejtö Faculty of Light Industry and Environmental Protection Engineering, Doberdó \\ út 6, 1034 Budapest, Hungary \\ ${ }^{c}$ Budapest University of Technology and Economics, Faculty of Mechanical Engineering, Department of Polymer \\ Engineering, Muegyetem rakpart 3, 1111 Budapest, Hungary \\ * corresponding author: csiszer.tamas@edutus.hu
}

\begin{abstract}
Modern welding processes that can easily be automated (such as friction stir welding, laser welding and ultrasonic welding) are gaining popularity in joining metal-polymer hybrid structures. This field of science is intensively studied around the globe, as a dependable, productive joining method that directly produces structurally sound joints between a metal and a polymer structure could unleash unforeseen possibilities in the vehicle industry.

In our experiments, we manufactured hybrid steel-poly(methyl-methacrylate) (PMMA) joints with laser welding, using the $2^{p}$ design of experiment method. We measured the effect of cellulose reinforcing fibres (in varying weight percentages) on the transparency and weldability of the PMMA material and the effect of welding parameters on the mechanical properties of the joints. We also examined the vicinity of the welded seam with scanning electron microscopy.
\end{abstract}

KEYwORDS: Laser welding, metal-polymer hybrid structures, poly(methyl-methacrylate).

\section{INTRODUCTION}

The importance of integrated structures made from dissimilar materials, for example by joining steel and polymer structures together is increasing in the vehicle industry. An advantage of these integrated structures is that less dense materials can be used, and thus vehicle manufacturing and operating costs can be reduced. However, the mechanical properties of the integrated structure must be comparable to the mechanical properties of the structure it replaced. Besides searching for compatible metal and polymer material pairs, a considerable amount of effort is made to convert and optimise existing joining technologies that can be automatized (for example friction stir welding [1 3 , ultrasonic welding [4], laser welding [7-10], and also a combination of laser and ultrasonic welding [11) to make them suitable for the mass production of integrated structures made from dissimilar materials. One factor that hinders this process is the fact that metals and polymers differ from each other both in physical structure and chemical composition and thus polymers and metals behave differently when joined together [12. If the polymer material contains additives, reinforcing fibres or nanofibers, the polymer's behaviour during joining (for example during laser irradiation) is even more complex [13].

Laser beams can be used in multiple ways during the processing and manufacturing of hybrid or integrated metal-polymer structures: depending on the laser welding machine and other parameters like laser power and beam velocity, laser beams can be used to cut materials, to process and to prepare their surfaces and also to join them together. The latter is usually called laser assisted metal polymer, or LAMP joining for short in publications [14].

The possibility of using laser welding to join metal and polymer structures together is already proven in publications [15. Rauschenberger et al. [8] proved that using the ideal process parameters during the joining of steel and polymer specimens (both reinforced and unreinforced) can result in even better joint strength than the strength of the polymer materials themselves. Jung et al. [16] joined zinc-coated steel and carbon fibre reinforced polyamide 6 : the ultimate shear force of the overlapped joint reached $3300 \mathrm{~N}$. Based on transmission electron microscopy (TEM) and energy dispersive X-ray spectroscopy (EDS), the authors claimed that the strength of the macroscopic joint was influenced by shape-connected mechanical joints: the molten polymer filled in the surface roughness grooves of the zinc coating. They also found that chemical bonding between zinc-oxide molecules and carbon atoms of the polymer chains further increased the joint strength. It is also stated by Cheon et al. [17] that the crystalline structure, the primary chemical bonding structure and the conformation of the polymer chains have a significant effect on the strength of metal-polymer joints. Bubbles can form in the polymer material during the joining process caused by the evaporation of remnant monomer molecules or 
additives (this phenomenon is called humping), which can strengthen or weaken joints depending on their quantity and size [18. Adhesion between the metal and polymer joining partners can be increased by structuring the joining surface of the metal specimen using a laser beam either to remove material from the surface [19, to transform material on the surface [20, 21], or to add material to the surface [5, 22]. It is also possible to use technologies like corona-discharge plasma treatment to chemically modify the surface of either the metal and/or the polymer specimens.

In our ongoing research, we joined structural steel to unreinforced and reinforced (with bio-based cellulose fibres in varying weight percentages) poly(methylmethacrylate) (PMMA) specimens using two different laser welding machines. Our aim was to identify and optimise the technological parameters that had a significant effect on the strength and appearance on the joint and to find and adjust measurement methods that are suitable for the measurement of the joints we made.

\section{Materials And Methods}

\subsection{Materials AND SPECimens}

Materials used in this work were structural steel (S235JR), $50 \times 10 \times 0.8 \mathrm{~mm}$ in dimension as metal specimen, and cellulose fibre-reinforced (in $0 \ldots 10 \mathrm{wt} \%$ ratio, whole numbers only) PMMA, $80 \times 10 \times 2 \mathrm{~mm}$ in dimension made by two manufacturers:

- The first PMMA type we used is sold under the trade name Sitramac HW55, a PMMA comonomerised with polystyrene (PS) made by Sitraplas GmbH,

- The second PMMA type we used is sold under trade name Altuglas VS-UVT, a pure and crystal-clear PMMA made by the Arkema Group.

Firstly, we measured the effect of cellulose fibres on the transparency and weldability of the PMMA material. For this, we manufactured cellulose fibre-reinforced specimens using the Sitramac base material and cellulose fibres manufactured by Kronospan-MOFA Hungary Ltd., using cellulose from multiple tree species. Both the PMMA pellets and the cellulose fibres were dried in a drying oven for 8 hours on $80^{\circ} \mathrm{C}$ (as specified by the manufacturers) before compounding on a twin-screw extruder (Labtech LTE 26-44, ascending temperature profile with $5{ }^{\circ} \mathrm{C}$ increments, temperature at the rod-type die: $200^{\circ} \mathrm{C}$ ). An endless filament was formed from the molten compounded material, which was pelletized for injection moulding on an Arburg Allrounder 270S 400-170 injection moulding machine. Standard (dogbone-shaped) tensile test specimens were manufactured.

Later on, we manufactured further reinforced and unreinforced specimens for testing and joining using both the Sitramac and the Altuglas VS-UVT base materials. The reinforcement we used was $1 w t \%$ cellulose fibre (manufactured by Arbocel under the trade name B600) with the same process parameters on the same twin-screw extruder and injection moulding machine. Flat, rectangular specimens $80 \times 80 \times 2 \mathrm{~mm}$ in dimension were injection moulded, from which, $80 \times 10 \times 2 \mathrm{~mm}$ specimens were cut using a disk cutting machine for joining.

\subsection{Experimental Methods}

As stated in the Introduction section, the chemical composition, material structure of the polymer and the reinforcing material can influence the behaviour of the specimen during laser welding, so we measured the transparency of the specimens to visible and nearinfrared (NIR) light on a Perkin-Elmer Lambda 1050 spectrophotometer. We found, that in the 950-1050 nanometre range (in which our laser welding machines operate), the direct transparency (the amount of light passing through the material without scattering) of the unreinforced specimens reached an average of $75 \%$ and $82 \%$ (for Sitramac and Altuglas base materials, respectively). When cellulose fibres were added to the base material in $1 w t \%$ ratio, the direct transparency of the specimens fell to an average of $35 \%$ and $22 \%$, respectively. Adding more than $1 w t \%$ cellulose fibres to the base material decreased the transparency so much that basically all the incident light scattered or were absorbed inside the material (see Figure 1).

We used two different laser welding machines to create two different kinds of overlapped joints between the steel and polymer specimens. All metal and polymer specimens were degreased and cleaned using methanol before joining. The first type of the overlapped joints was manufactured with the so-called transmission welding process, in which the polymer specimen is placed on top of the steel specimen. In this case, the laser beam passes through the polymer and then it is absorbed in the steel specimen, creating heat. The heat is then conducted to the polymer specimen, which in turn melts and fills in the surface roughness grooves of the steel, forming shape-connected (mechanical) joints. The second type of process we used was the so-called direct laser welding. In this process, the polymer specimen is placed below the steel specimen, while the latter is irradiated and heated up by the laser beam. With this method, higher laser power outputs may be used and thus, faster cycle times can be achieved without the degradation of the polymer material. We used a Trumpf TruDiode 151 diode laser with a maximum power output of $150 \mathrm{~W}$ for the transmission welding process, and a Trumpf TruDisk 4001 (Yb:YAG) solid state laser with a maximum power output of $4000 \mathrm{~W}$ for the direct laser welding process. The main process control parameter was the laser power. During the transmission welding with the diode laser, laser power was set to 30,40 and $50 \mathrm{~W}$, while during the direct laser welding with the solid 


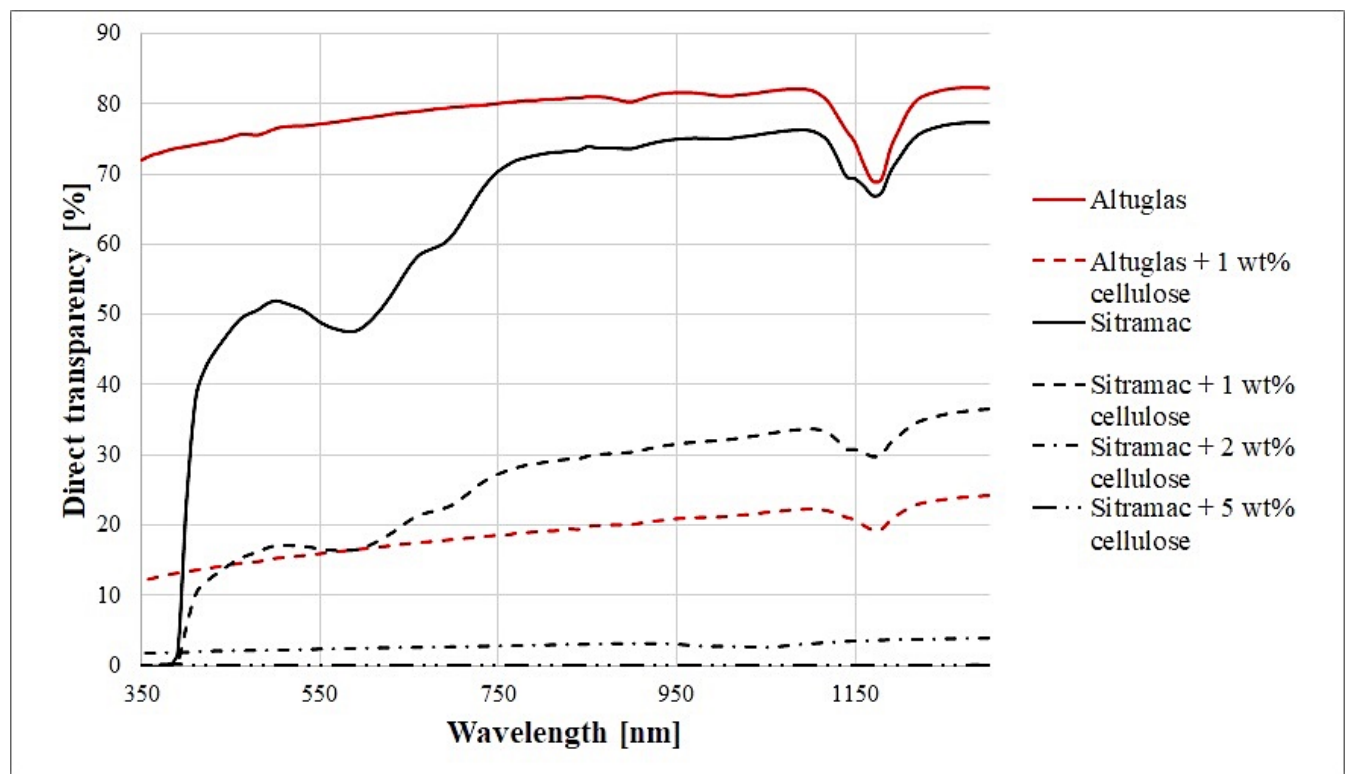

FIGURE 1. Direct transparency of unreinforced and reinforced PMMA specimens

\begin{tabular}{cc}
\hline Rate & Meaning \\
\hline 0 & No data \\
1 & No flame \\
2 & Small flame \\
3 & Moderate flame \\
4 & Heavy flame \\
\hline
\end{tabular}

TABLE 1. The qualification of flaming rates

state laser, laser power was set to 210,230 and $250 \mathrm{~W}$. These values were chosen based on preliminary measurements we conducted. We used the $2^{p}$ design of experiment method to manufacture a total of 200 steelPMMA specimens. All other parameters remained constant during the joining process: the specimens were joined in 3 cycles in a straight, $10 \mathrm{~mm}$ line, while the welding speed was set to $1 \mathrm{~m} / \mathrm{min}$. Investigating the mechanical (shear) strength of the joined specimens is ongoing. In the next section, we will present a qualitative analysis of the joined specimens and some preliminary results.

\section{Discussion}

In most cases during the direct welding process, the polymer specimens burst into flames. The degree of flaming was qualified according to its intensity (see Table 1) with visual inspection during the welding process.

Applying $250 \mathrm{~W}$ of laser power, the average rates of intensity of flaming were between 3 and 3.5 for each matrix-fibre combination, which proves the presumption that higher energy input can cause the intensive degradation of the polymer, which can lead to flaming. On lower laser power levels (at 210 and $230 \mathrm{~W}$ ), the flame intensity of the materials were similar, except for the Sitramac PMMA reinforced with $1 w t \%$ cellu-

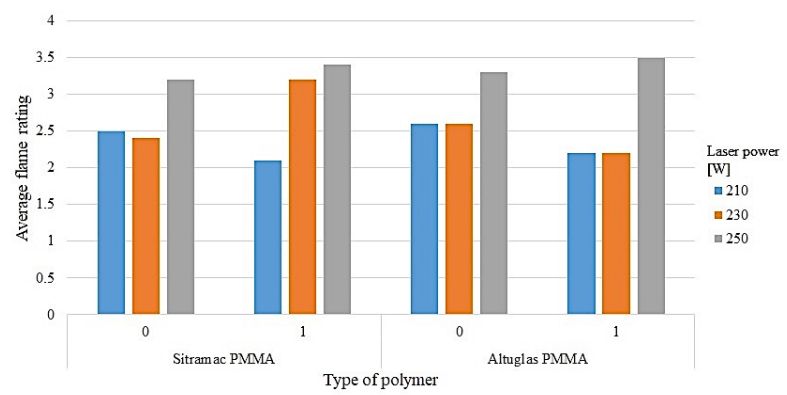

Figure 2. Average flaming rates during direct laser welding of steel-PMMA specimens

lose fibres at $230 \mathrm{~W}$ laser power (Figure 2). A possible reason for this phenomenon can be that the chemical composition of the Sitramac PMMA differs from that of the Altuglas PMMA.

Based on the tensile shear testing of overlapped joints made by the solid-state laser with $250 \mathrm{~W}$ laser power between unreinforced (Sitramac) PMMA and steel, we can say that the joints are quite rigid and standard deviations of both ultimate shear force and displacement values are high (Figure 3). This may be caused by inadequate contact (air gap) between specimens during joining, or the fact that the material surfaces were only degreased before the joining process. In later experiments, we made sure that there wasn't an air gap between specimens during joining, and we are planning on trying different techniques to prepare the surfaces of the specimens in the hopes of reaching better shear strength values.

We also noticed that after the tensile shear tests, some PMMA remained on the steel specimen's surface. Using a scanning electron microscope (SEM), we discovered that the connection between the steel and PMMA was not evenly distributed on the join- 


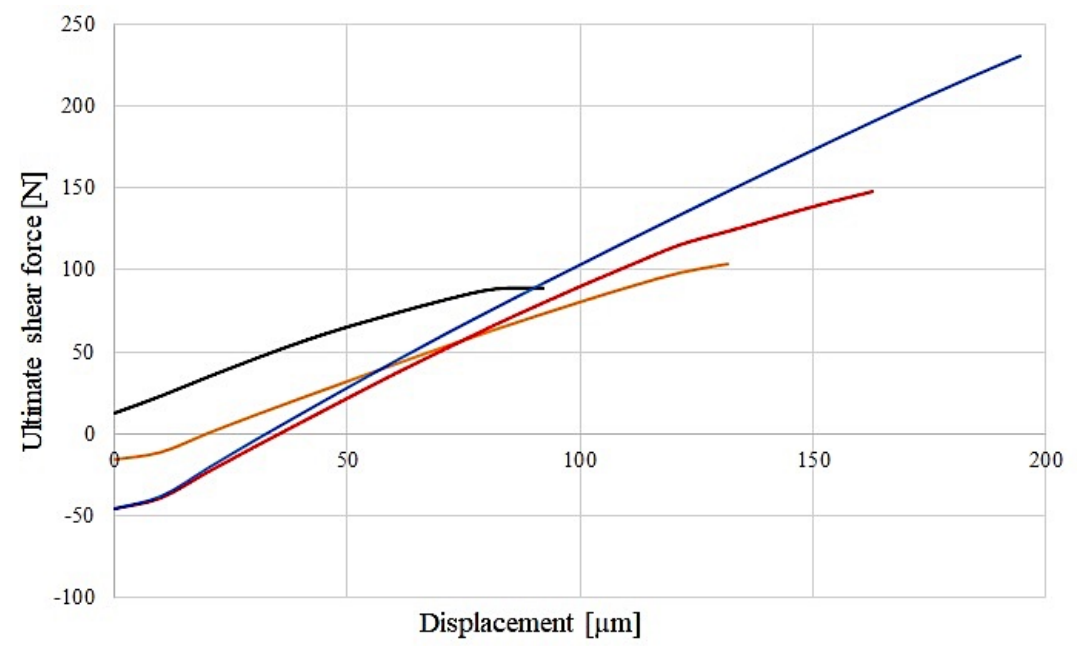

FiguRE 3. Ultimate tensile-shear force values of unreinforced PMMA-steel specimens

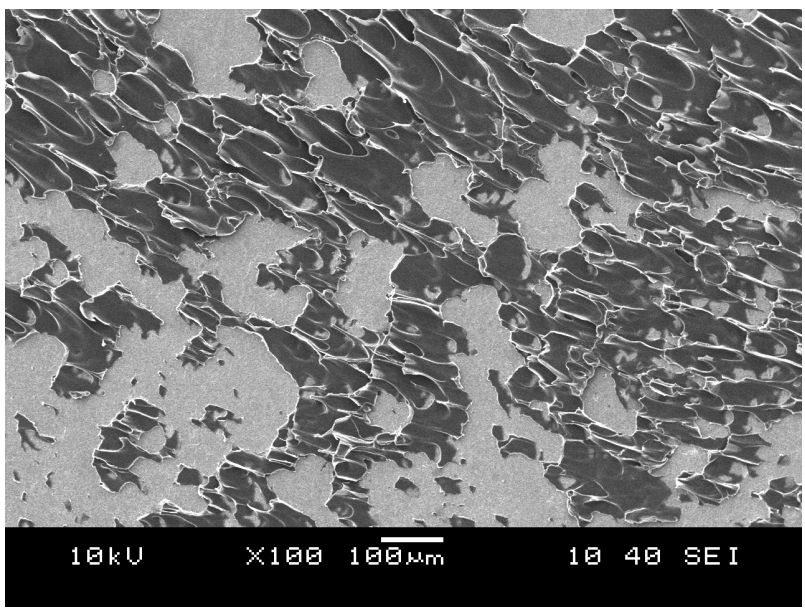

Figure 4. Cohesive failure of the PMMA near the steel-polymer interface (SEM image of the steel surface)

ing surface. In some areas, the adhesion between the materials was so good, that the failure was inside the PMMA material (as shown in Figure 4, where the plastic deformation of the PMMA material can be seen), while in other areas, the joint failed with simple adhesive failure (debonding) on the interface. The PMMA material also possibly degraded: the formation of gas bubbles on and near the joint interface can clearly be seen in Figure 5 , however, at lower laser power values, no joints could be manufactured. The degree of degradation of the PMMA and the possibility of forming chemical bonds between the materials needs to be investigated further.

\section{Conclusions}

With our experiments, we proved that it is possible to manufacture joints between PMMA and steel specimens with laser welding equipment. Both the transmission welding (when the laser beam passes through the polymer material) and the direct laser welding (when the laser beam does not pass through

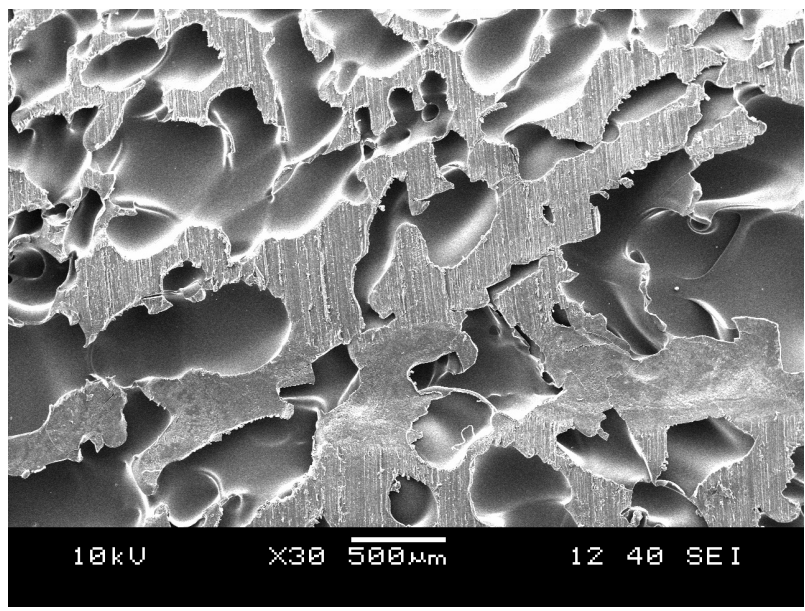

Figure 5. Gas bubbles on and near the steel-polymer interface and adhesive failure of the PMMA (SEM image of the PMMA surface)

the polymer) techniques could be used to join the specimens. We also proved that cellulose fibres greatly decreased the direct transparency of the otherwise crystal clear PMMA material even at low weight percent ratios, thus making the transmission welding joining of reinforced PMMA and steel specimens difficult and time-consuming.

The steel-polymer joints we manufactured were rigid and the standard deviation of measured tensile force values were high, which was possibly caused by the degradation of the PMMA material during welding and the uneven connection between PMMA and steel in the joint area. In most cases during the direct welding process, the polymer specimens burst into flames, which also decreased joint strength. The two prominent failure modes were adhesive failure (debonding) on the joint interface and cohesive failure of the PMMA material. 


\section{ACKNOWLEDGEMENTS}

This research was supported by the grant No. EFOP3.6.1-16-2016-00009 and by the UNKP-18-3 New National Excellence Program of the Ministry of Human Capacities of Hungary under grant no. ÚNKP-18-3-IBME-183.

\section{REFERENCES}

[1] F. Khodabakhshi, M. Haghshenas, S. Sahraeinejadand, et al. Microstructure-property characterization of a friction-stir welded joint between aa5059 aluminum alloy and high density polyethylene. Materials Characterization 98:73-82, 2014. DOI:10.1016/j.matchar.2014.10.013

[2] H. Shahmiri, M. Movahedi, A. H. Kokabi. Friction stir lap joining of aluminium alloy to polypropylene sheets. Science and Technology of Welding and Joining 22:120-126, 2016. DOI:10.1080/13621718.2016.1204171

[3] H. A. Derazkola, R. K. Fard, F. Khodabakhshi. Effects of processing parameters on the characteristics of dissimilar friction-stir-welded joints between aa5058 aluminum alloy and pmma polymer. Welding in the World 62:117-130, 2018. DOI:10.1007/s40194-017-0517-y

[4] F. Balle, G. Wagner, D. Eifler. Ultrasonic metal welding of aluminium sheets to carbon fibre reinforced thermoplastic composites. Advanced Engineering Materials 11:35-39, 2009. DOI:10.1002/adem.200800271.

[5] P. N. Parkes, R. Butler, J. Meyer, A. de Oliveira. Static strength of metal-composite joints with penetrative reinforcement. Composite Structures 118:250-256, 2014. DOI:10.1016/j.compstruct.2014.07.019

[6] R.-Y. Yeh, R.-Q. Hsu. Development of ultrasonic direct joining of thermoplastic to laser structured metal. International Journal of Adhesion and Adhesives 65:28-32, 2016. DOI:10.1016/j.ijadhadh.2015.11.001.

[7] S. Katayama, Y. Kawahito. Laser direct joining of metal and plastic. Scripta Materialia 59:1247-1250, 2008. DOI:10.1016/j.scriptamat.2008.08.026

[8] J. Rauschenberger, A. Cenigaonaindia, J. Keseberg, et al. Laser hybrid joining of plastic and metal components for lightweight components. High-Power Laser Materials Processing: Lasers, Beam Delivery, Diagnostics, and Applications IV, Proceedings of SPIE, vol 9356 2015. DOI:10.1117/12.2080226

[9] F. Lambiase, S. Genna. Laser-assisted direct joining of aisi304 stainless steel with polycarbonate sheets: Thermal analysis, mechanical characterization, and bonds morphology. Optics and Laser Technology 88:205-214, 2017. DOI:10.1016/j.optlastec.2016.09.028

[10] F. S. Noh, H. M. Zin, K. Alnasser, et al. Optimization of laser lap joining between stainless steel 304 and acrylonitrile butadiene styrene (abs). Procedia Engineering 184:246-250, 2017. DOI:10.1016/j.proeng.2017.04.092

[11] Y. J. Chen, T. M. Yue, Z. N. Guo. Laser joining of metals to plastics with ultrasonic vibration. Journal of Materials Processing Technology 249:441-451, 2017. DOI:10.1016/j.jmatprotec.2017.06.036.
[12] S. T. Amancio-Filho, L. Blaga. Joining of polymermetal hybrid structures - principles and applications. John Wiley and Sons, Inc., Hoboken, New Jersey, United States of America, 2018. DOI:10.1002/9781119429807.

[13] T. Csiszér, T. Temesi, L. Molnár. A (monokromatikus) fény az alagút végén - részeredmények a fém-polimer hibrid szerkezetek lézersugaras technológiájában. Acta Periodica 15:75-85, 2018.

[14] D.-J. Jung, J. Cheon, S.-J. Na. Effect of surface pre-oxidation on laser assisted joining of acrylonitrile butadiene styrene (abs) and zinc-coated steel. Materials and Design 99:1-9, 2016. DOI:10.1016/j.matdes.2016.03.044

[15] T. Temesi, Z. Kiss, T. Csiszér. Korszerü technológiák fém és polimer anyagok közötti kötések kialakítására. Acta Periodica 15:115-125, 2018.

[16] K. W. Jung, Y. Kawahito, M. Takasashi, S. Katayama. Laser direct joining of carbon fiber reinforced plastic to zinc-coated steel. Materials and Design 47:179-188, 2013. DOI:10.1016/j.matdes.2012.12.015

[17] J. Cheon, S. J. Na. Relation of joint strength and polymer molecular structure in laser assisted metal and polymer joining. Science and Technology of Welding and Joining 19:631-637, 2014. DOI:10.11779/1362171814Y.0000000236

[18] P. Berger, H. Hügel, A. Hess, et al. Understanding of humping based on conservation of volume flow. Physics Procedia 12:232-240, 2011. DOI:10.1016/j.phpro.2011.03.030

[19] E. Rodríguez-Vidal, C. Sanz, C. Sariano, et al. Effect of metal micro-structuring on the mechanical behavior of polymer-metal laser t-joints. Journal of Materials Processing Technology 229:668-677, 2016. DOI:10.1016/j.jmatprotec.2015.10.026.

[20] J. Blackburn, P. Hilton. Producing surface features with a $200 \mathrm{w}$ yb-fibre laser and the surfi-sculpt ${ }^{\circledR}$ process. Physics Procedia 12:529-536, 2011. DOI:10.1016/j.phpro.2011.03.065

[21] Z. Zhang, J. Shan, X. Tan, J. Zhang. Improvement of the laser joining of cfrp and aluminum via laser pre-treatment. The International Journal of Advanced Manufacturing Technology 90:3465-3472, 2016. DOI:10.1007/s00170-016-9646-5.

[22] D. P. Graham, A. Rezai, D. Baker, et al. The development and scalability of a high strength, damage tolerant, hybrid joining scheme for composite-metal structures. Composites Part A: Applied Science and Manufacturing 64:11-24, 2014. DOI:10.1016/j.compositesa.2014.04.018. 